\title{
Cyanotic complex congenital heart disease presenting with brain abscess at the age of 19: A case report and review of literature
}

\author{
Khandker Md Nurus Sabah¹, Abdul Wadud Chowdhury², Mohammad Shahidul Islam³, Mohsin Ahmed ${ }^{4}$, \\ Gaffar Amin ${ }^{5}$, Kazi Nazrul Islam ${ }^{6}$, Shamima Kawser ${ }^{7}$, H. I. Lutfur Rahman Khan ${ }^{8}$, Mohammed Abaye Deen Saleh ${ }^{9}$, \\ Zayed Mahbub Khan ${ }^{10}$
}

\begin{abstract}
:
Introduction: Brain abscess is a complication of congenital cyanotic heart disease with or without shunt anomaly. It is more common in children. Here, we delineated a case of 19-year-old young Bangladeshi Bengali male who presenting with brain abscess, an unusual presentation of cyanotic complex congenital
\end{abstract}

heart disease. This case report focuses not only on the unusual presentation of congenital heart disease but also emphasizes the importance of early recognition of neurological complication for referal management.

Key words: Heart defects, Congenital, Cyanosis, Brain, Abscess.

\section{Case presentation:}

A 19-year-old Bangladeshi male presented with fever, cough, and breathlessness for 2 weeks, headache, confusion and focal convulsion confined to right side of face for 4 days. He had mild dehydration, congested conjunctiva, pulse- $136 \mathrm{bpm}$, blood pressure- 90/60 mm $\mathrm{Hg}$, temperature- $105^{\circ} \mathrm{F}$, grade 4 clubbing, cyanosis and

1. Assistant Professor, Department of Cardiology, Dhaka Medical College Hospital

2. Professor \& Head, Department of Cardiology, Dhaka Medical College Hospital

3. Department of Cardiology, Dhaka Medical College Hospital

4. Associate Professor, Department of Cardiology, Dhaka Medical College Hospital

5. Assistant Professor, Department of Cardiology, Dhaka Medical College Hospital

6. Junior Consultant, Department of Cardiology, Dhaka Medical College Hospital

7. Associate Professor, Department of Microbiology, Dr. Sirajul Islam Medical College Hospital

8. Professor, Department of Cardiology, Anwer Khan Modern Medical College Hospital Ltd.

9. Registrar, Department of Cardiology, Dhaka Medical College Hospital

10. Assistant Registrar, Department of Cardiology, Dhaka Medical College Hospital oxygen saturation $81 \%$, features of pulmonary stenosis, tricuspid atresia in precordium and Glasgow coma scale$10 / 15$, rigid neck, bilateral planter extensor, bilateral early papilloedema and crackles of right side of back of the

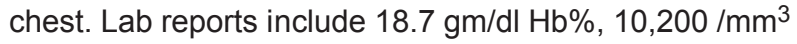
white cell count with $75 \%$ neutrophils. There was pneumonic consolidation of right side in chest X-ray and sinus tachycardia, left axis deviation, short PR interval and features of right atrial enlargement in electrocardiogram. Doppler echocardiogram revealed tricuspid atresia, rudimentary right ventricle, large ventricular septal defect, severe valvular pulmonary stenosis, atrial septal defect, persistent left superior vena cava with ejection fraction $63 \%$. CT scan of brain revealed a cerebral abscess in left frontal lobe with mass effect; the lesion was operated through bar hole. Culture of pus revealed Enterococcus faecalis. Persistent abscess was noted on repeat CT scan after 3 weeks. Unfortunately, patient died despite giving appropriate treatment with proper antibiotic according to pus culture and antibiotic sensitivity report.

Conclusion: Congenital heart disease with right to left shunt should be considered if a young patient presents with brain abscess without presence of other risk factors. 
During follow-up or $1^{\text {st }}$ time visit of congenital cyanotic heart disease, development of focal neurological deficits without any residual deficits or evidence of raised intracranial pressure should be monitored.

\section{Background:}

Brain abscess is a rare but well-recognized, serious life threatening complication of cyanotic congenital heart disease. It is more common in children ${ }^{1}$. Its mortality rate is high in the setting of cyanotic congenital heart disease, even in the modern era ${ }^{2}$. Here, we described a case of 19-year-old young Bangladeshi male who had undetected cyanotic complex congenital heart disease presenting with brain abscess. We emphasized on this type of presentation of congenital heart disease as it is uncommon and early detection of neurological complication in this settings gives better outcome.

\section{Case Presentation:}

A 19-year-old young Bangladeshi garments worker was admitted to Department of Cardiology, Dhaka Medical College Hospital with the complaints of fever, cough, shortness of breath for 2 weeks and headache, altered mental status, focal convulsion for 4 days. His fever came without chills and rigor, was high grade from the $1^{\text {st }}$ day of symptoms, maximum recorded temperature $105^{\circ} \mathrm{F}$, persisted whole day with a $2^{0} \mathrm{~F}$ fluctuation even after taking anti-pyretic drugs. It was associated with cough which was dry and worsening day by day. It had no precipitating factors, not associated with chest pain, hemoptysis, wheeze, nasal symptoms, hoarseness of voice, dyspepsia, heartburn, skin rash, weight loss. He also had shortness of breath on exertion for the same duration, which came on gradually, was constant and worsening. Later he felt it even on rest. It was not associated with any precipitating or relieving factors, chest pain, pre-syncope or syncope, orthopnoea, oedema, any vasculitic symptoms, pruritus. His functional status was New York Heart Association (NYHA) class IV. For last 4 days, he had severe headache that developed gradually, persistent over whole day, more on morning and during straining. Later, He became drowsy and developed focal convulsion. Convulsion occurred several times with preceding history of forced head and eye turning to left side and was only confined to right side of face; each episode persisted for 5- 10 seconds. Neurological features were not associated with rash, limb weakness, visual disturbances, dysphasia, nausea, vomiting, recent ear and upper respiratory tract infection, head trauma. On query, patient's mother gave history of presence of cyanosis and clubbed fingers since his childhood. Otherwise he had normal developmental milestones and no history of chest infection and family history of heart disease. He was non-smoker, nonalcoholic in personal life. He took a drug- combination of amoxicillin/ clavulanic acid for 5 days and paracetamol before admission but there was no improvement. On admission, he was mildly dehydrated, having below average body build, congested conjunctiva, regular pulse at a rate of $136 \mathrm{bpm}, 90 / 60 \mathrm{~mm} \mathrm{Hg}$ blood pressure, $105^{0}$ $\mathrm{F}$ surface body temperature, grade 4 clubbing, marked cyanosis in lips, tongue and nail bed and $\mathrm{SpO}_{2} 81 \%$ in room temperature and no stigmata of infective endocarditis. He had features of pulmonary stenosis- a widely split S2, with a soft and delayed P2 with a systolic ejection murmur of grade $\mathrm{V}$, more prominent in the left $3^{\text {rd }}$ intercostals space that increased with inspiration and radiates diffusely along with both right and left upper sternal border and in back of chest and features of tricuspid atresia - hyperdynamic apical impulse without displacement and loud $1^{\text {st }}$ heart sound. Besides this, there was also a systolic thrill in right $1^{\text {st }}$ and $2^{\text {nd }}$ Intercostal space along with right upper sternal border. He had 10/15 GCS (E3, M6, V1), sign of meningeal irritation (neck rigidity), features of upper motor neuron lesion- bilateral early papilloedema and bilateral extensor planter response. He also had vesicular breath sound and crackles from $7^{\text {th }}$ intercostals space down to the right side of back of the chest.

Marked cyanosis, clubbing and features of vulvular heart disease lead to the diagnosis of congenital cyanotic heart disease. Neurological findings in this setting were thought to be done to meningoencephalitis complicated by brain abscess. Clinical findings of chest were thought to be pneumonia.

Complete blood count revealed $18.7 \mathrm{gm} / \mathrm{dl} \mathrm{Hb} \%, 05 \mathrm{~mm}$ of $\mathrm{Hg}$ ESR, $10,200 / \mathrm{mm}^{3}$ white cell count with $75 \%$ neutrophils, $17.6 \%$ lymphocytes. Serum electrolytes, serum creatinine, serum urea and serum ALT were within normal limits. Chest $x$ - ray revealed inhomogeneous opacity in right mid and lower zones, cardiac shadow was normal in transverse diameter, right ventricular type apex, reduced broncho-vascular markings.

In electrocardiogram, there were sinus tachycardia, left axis deviation, short PR interval, right atrial enlargement. Colour Doppler echocardiogram revealed tricuspid atresia, rudimentary right ventricle, large ventricular septal defect ( perimembranous and muscular), severe pulmonary stenosis (valvular type), atrial septal defect 
(coronary sinus type), persistent left superior vena cava, normal atrioventricular and ventriculoarterial relationship, normal great artery relationship, good left ventricular systolic function with ejection fraction $63 \%$.

There was also no growth in blood culture. Due to neurological manifestations, we did a CT scan of brain that revealed a large oval shaped hypodense mass lesion with perilesional oedema measuring about $7 \times 5 \times 4$ $\mathrm{cm}^{3}$ in size situated in the left frontal area and mass effect evident by compression on adjacent brain parenchyma with contralateral midline shift suggestive of cerebral abscess in left frontal lobe with mass effect. This was managed by draining through bar hole under general anaesthesia done by Department of Neurosurgery of same institute. Gram stain of pus revealed gram positive cocci and culture of pus showed enterococcus faecalis sensitive to ampicillin, gentamicin, penicillin $G$ and vancomycin. He was treated with gentamicin and vancomycin. Three weeks later, again CT scan was done revealing persistent abscess. For that, repeat drain of brain abscess was suggested by Department of Neurosurgery. Preparation for $2^{\text {nd }}$ time drain of brain abscess and cardiac catheterization after recovery from brain abscess was taken. Unfortunately, patient died before that the caregivers were not agreed to do a post-mortem evaluation.

\section{Case discussion:}

Brain abscess is a focal, intracerebral infection that begins as a localized area of infection and develops into a collection of pus surrounded by a well-vascularized capsule $^{3}$. In 1814, Ferry described a case of brain abscess in congenital cyanotic heart disease for the first time in medical history 4 . It is an uncommon complication of congenital heart disease, mostly associated with untreated cyanotic congenital heart disease. Even in Bangladesh where most of the congenital heart diseases are undiagnosed and untreated, brain abscess is not common as a complication. In one study of 162 cases of brain abscess treated in different hospitals of Dhaka, Bangladesh in between 1999 to 2013, congenital heart disease is responsible in only $6.17 \%$ cases $^{5}$. It is necessary to mention that cyanotic heart disease accounts for up to $69.1 \%$ of all cases of brain abscesses associated with higher incidence in children and peak incidence in between 4 to 7 years of age ${ }^{1,6}$. Most series revealed 1.5 to 2.5 times a male preponderance over female in general population ${ }^{7,8}$. This 19-year-old male having no significant history related to complex congenital cyanotic heart disease presented to us with brain abscess. The age and the way of presentation enriched our knowledge as he had no significant symptoms of heart disease.

It is most commonly seen in tetralogy of fallot ${ }^{5,6}$. However, any condition resulting in a significant right to left shunt appears to increase the risk. Though the abnormality couldn't be fully identified by colour Doppler and M Mode echocardiography in this case, it revealed coronary sinus type atrial septal defect, large perimembranous and muscular ventricular septal defect, tricuspid atresia. Why does brain abscess occur in cyanotic heart disease? It is always secondary to bacteremia. Bacteria in the bloodstream are not filtered through the pulmonary circulation due to right to left shunt of venous blood in heart, it is prone to seeding in brain, especially in the low- perfusion area " in the junction of gray and white matter" and are often poorly encapsulated. This abscess also shows a predilection for the territory of the middle cerebral artery ${ }^{9}$.

The classic triad of presentation of brain abscess is headache, fever and a focal neurologic deficits, present only in less than $20 \%$ cases in one study. Localizing neurological signs occur relatively late in the course of the illness. It is usually solitary. However, due to hemoatogenous spread, multiple numbers of abscesses are often encountered. In presence of cyanotic heart disease, the most common organisms are viridans streptococci, including the Streptococcus milleri, Streptococcus aureus, Haemophilus and occasionally Enterococci ${ }^{9}$. Atiq el al revealed Streptococcus milleri was most common in patients with cyanotic heart disease ${ }^{11}$. Multiple organisms have also been reported ${ }^{12,13}$. In this case, gram stain of pus showed gram positive cocci and in culture, gram positive organism Enterococci faecalis was isolated.

In case of enterococcal disease, bacteremia and endocarditis are common presentations. It accounts for $5 \%-20 \%$ of cases of endocarditis after Streptococcus aureus. There is a low possibility of endocarditis in this case as there was no clinical signs and evidence of endocarditis in colour Dopper and $M$ mode echocardiography. Other than endocarditis, frequent sources of the bacteremia are usually the genitourinary and gastrointestinal tracts in patients with infections originating outside the hospital. There is a possibility of Enterococcal pneumonia supported by clinical signs and radiological features causing bacteraemia in this case though it is rare. It is also noted that it is an uncommon cause of meningitis with complication- brain abscess. Other complications of enterococcal meningitis are hydrocephalus and stroke ${ }^{14}$. 
As cyanotic heart disease compromises cardiovascular system, the related patients are not a good candidate for general anesthesia. The mortality rate is very high. Following craniotomy and excision, it was $71 \%{ }^{15}$. Nearly $17 \%$ of patients after aspiration develop cyanotic spells and may develop life-threatening complications ${ }^{13}$. The mortality rate was decreased over the past few decades, from around $70 \%$ to around $10 \%$ due to use of neuroimaging in the management of brain abscess ${ }^{2}$. Early detection, availability of image guidance for aspiration and better radiological follow-up during the course of the antibiotic therapy is responsible to this achievement though the prognosis is dependent on the rapidity of progression of disease before hospitalization and patient mental status on admission ${ }^{2}$.

\section{Conclusion:}

Congenital heart disease with right to left shunt is one of risk factors for brain abscess and outcome is poor if it is diagnosed late. Development of focal neurologic abnormalities or evidence of raised intracranial pressure should be evaluated for presence of brain abscess.

\section{Consent:}

Written informed consent was obtained from the patient caregivers for the publication of this case report. A copy of the written consent is available for review by the editor of this journal.

\section{Competing Interests}

The authors declare that they have no competing interests.

\section{Authors' Contributions}

KMNS is the first author and was involved in the diagnosis of the case and writing a part of the manuscript. MSI is the communicating author and involved in drafting the manuscript. MAS, SK revised it critically and involved in the management of patient. HILRK did echocardiography and tried to reveal the riddle. AWC provided overall support. All the authors have read and approved the final manuscript.

\section{Acknowledgement}

We acknowledge all the clinical staff of Department of Neurosurgery, Dhaka Medical College Hospital for cordial co-operation in this case.

None of authors have received any grant from any funding agency in the public, commercial, or not-forprofit sectors.

\section{References:}

1. Kagawa M, Takeshita M, Yato S, Kitamura K. Brain abscess in congenital cyanotic heart disease. J Neurosurg. 1983; 58: 913-7. http://dx.doi.org/ 10.3171/jns.1983.58.6.0913.

2. Seydoux C, Francioli P. Bacterial brain abscesses: Factors influencing mortality and sequelae. Clin Infect Dis. 1992; 15: 394-401. http://dx.doi.org/ 10.1093/clind/15.3.394.

3. Mathisen GE, Johnson JP. Brain abscess. Clin Infect Dis. 1997; 25: 763-779. http://dx.doi.org/10.1086/ 515541

4. Farre JR. Malformation of the heart, or its arteries, mingling black with red blood: ostium aorta, communicating with both ventricles. In: Pathological researches on malformations of the Human Heart. London: Longmans, Hurst, Rees, Orme and Brown, Paternoster-row; 1814. p. 24-6.

5. Chowdhury FH, Haque MR, Sarkar MH, Chowdhury Sm, Hossain Z, Ranjan S. Brain Abscess: Surgical Experiences of 162 Cases. Neuroimmunol Neuroinflammation. 2015; 2: 153-61. http:// dx.doi.org/10.4103/2347-8659.160851.

6. Takeshita M, Kagawa M, Yato S, Izawa M, Onda H, Takakura K, Momma K. Current treatment of brain abscess in patients with congenital cyanotic heart disease. Neurosurgery. 1997; 41: 1270-8. http:// dx.doi.org/10.1097/00006123-199712000-00006.

7. Aebi C, Kaufmann F, Schaad UB. Brain abscess in childhood-long-term experiences. Euro J Pediatr. 1991; 150: 282-6. http://dx.doi.org/10.1007/ BF01955533.

8. Berlit P, Fedel C, Tornow K, Schmiedek P. The bacterial brain abscess - experience in 67 patients. Fortschr Neurol Psychiatr. 1996; 64:297-306. http:/ /dx.doi.org/10.1055 / s-2007-996398.

9. Roos KL, Tyler KL. Meningitis, encephalitis, brain abscess, and empyema: Brain abscess. In: Kasper DL, Hauser SL, Jameson JL, Fauci AS, Longo DL, Loscalzo J, editors. Harrison's principles of internal medicine, $19^{\text {th }}$ ed. New York: McGraw-Hill Education; 2015. p. 900-2.

10. Menon S, Bharadwaj R, Chowdhary A, Kaundinya DV, Palande DA. Current epidemiology of intracranial abscesses: a prospective 5 year study. $J$ 
Med Microbiol. 2008; 57: 1259-68. http://dx.doi.org/ 10.1099/jmm.0.47814-0.

11. Atiq M, Ahmed US, Allana SS, Chishti KN. Brain abscess in children. Indian J Pediatr. 2006; 73: 4014. http://dx.doi.org/10.1007/BF02758560

12. Prusty GK. Brain abscesses in cyanotic heart disease. Indian J Pediatr. 1993; 60: 43-5. http:// dx.doi.org/10.1007/BF02860506

13. Shahzad K, Hamid MH, Khan MA, Malik N, Maqbool S. Brain abscess in children. J Coll Physicians Surg Pak. 2005; 15: 609-11.
14. Arias CA, Murray BE. Enterococcus species, streptococcus gallolyticus group, and leuconostoc species. In: Bennett JE, Dolin R, Blaser MJ, editors. Mandell, Douglas and Bennett's principles and practice of Infectious diseases. $8^{\text {th }}$ ed. Philadelphia: Saunders, an imprint of Elscevier Inc; 2015. p. 2328-39.

15. Itakura T, Yokote H, Ozaki F, Itatani K, Hayashi S, Komai N. Stereotactic operation for brain abscess. Surg Neurol. 1987; 28: 196- 200. http://dx.doi.org/ 10.1016/0090-3019(87)90133-9. 